\title{
Aesthetic/Cosmetic Surgery and Ethical Challenges: The Social Media Era
}

\author{
B. Atiyeh ${ }^{1}$ - A. Ibrahim ${ }^{1}$
}

Published online: 5 August 2020

(C) Springer Science+Business Media, LLC, part of Springer Nature and International Society of Aesthetic Plastic Surgery 2020

Discussing the paper entitled "Aesthetic/Cosmetic Surgery and Ethical Challenges", Mendelson [1] stated that "the central thesis of the review is whether aesthetic plastic surgery remains where it commenced, in the realm of the medical system where it was intended to seriously benefit patients, or whether it should cross into the commercial world, which contrasts in having the immediate focus on benefiting the business". He added also "the immense challenges from the media, consumer advertising, opportunist nonspecialist practitioners, and commercial interests are testing the traditional ethics under which plastic surgeons trained". The concerns Mendelson has raised more than a decade ago still hold today with the rapid expansion of non-core aesthetic plastic surgery disciplines such as "aesthetic medicine", "dermatologic surgery", "facial plastic surgery", "oculoplastic surgery", "aesthetic gynecology", and even now "oncoplastic surgery".

Aesthetic plastic surgery is evolving rapidly and plastic surgeons are being confronted with new technological and conceptual challenges in addition to fierce competition from plastic surgery colleagues as well as from a multitude of non-plastic surgery practitioners that have gained expertise in fields traditionally served by plastic surgeons [2]. These challenges are rapidly gaining in severity with the exponential increase in promotion and marketing

\footnotetext{
B. Atiyeh

bechara.atieh@gmail.com

1 Beirut, Lebanon
}

strategies on the various electronic platforms and social media by non-plastic surgeons [2].

The specialty of plastic surgery encompasses a wide and diverse breadth of clinical expertise including both reconstructive and aesthetic procedures. Unfortunately, diversity in clinical proficiency and practice has been confusing, and the role of plastic surgeons in patient care has not been completely perceived, particularly by primary care physicians who are a fundamental source of patients' referral and of information [3]. As subspecialization continues and overlap of clinical practice with other specialties increases in the fields of aesthetic medicine and facial aesthetic surgery, plastic surgeons are at notably greater risks of not being considered as primary care providers and specialists for many procedures. This state of affairs most probably is a reflection of publicity, aggressive marketing, promotion, and education by other practitioners [3]. Aesthetic plastic surgeons are compelled in order to maintain a competitive edge, to keep their promotional, marketing, and educational activities commensurate with those of their competitors [3]. To prevent noncore practitioners from monopolizing communication, plastic surgeons must be urged to keep engaging with patients online [4,5]. Failing to do so may lead those patients to seek the services of less qualified "cosmetic surgeons" [4].

Culture and social engagement witnessed drastic changes since the advent of Facebook in 2004 [4] and in the era of rapidly spreading and constantly evolving electronic and social media platforms together with fierce competition by noncore specialties, aesthetic plastic surgery is facing an identity crisis [6]. Apparently, the days of relying on 
physician referrals, word of mouth, and academic pedigrees and achievements for practice building in plastic surgery are long gone [7]. We are now amidst an unstoppable shift in social mindset and consciousness, and there is no doubt that electronic platforms and social media are here to stay [8]. Patients are relying more on social media for advice and decision-making regarding plastic surgery procedures $[9,10]$. Likewise, to attract new patients in an increasingly competitive market and promote practice and services, as well as branding, educating the public, and communicating directly with patients, practitioners are mostly relying at present on electronic marketing with great emphasis on social media rather than special practice websites or other traditional electronic marketing platforms $[4,7]$. Social media will continue to evolve and will certainly generate new challenges [8]. Plastic surgeons have the obligation to follow this evolution if they care to maintain their capacity to accurately reach a potentially infinite audience. They have the obligation as well to maintain a professional and ethical conduct and respect patient privacy $[6,8]$.

Increasing social media use by aesthetic plastic surgeons in an increasingly competitive market has led to mounting significant public apprehensions. Social media is not without significant risk and may entail real and serious legal implications if not used with caution [4]. It certainly has many negative aspects; it can be very difficult if not impossible to monitor, control, and regulate, but can be readily and easily abused. Nevertheless, in order to keep providing accurate information about procedures and to remain relevant to patients, it is imperative that plastic surgeons adapt to the evolving cultural trends of society while exercising strict discernment regarding content of their social media posts [4]. Undoubtedly, sensationalist content that may be posted by some will only serve to cause more harm to aesthetic plastic surgery already scandalously portrayed by the media on many occasions [4].

Little has been reported about ethical implications with regard to video sharing and live broadcasts of aesthetic plastic surgery operations on social media applications such as Snapchat, Instagram, and YouTube. These, besides being viewed as entertaining rather than representation of patient care, may constitute potential but serious breaches of patient confidentiality [10]. Moreover, photographs and videos graphically capturing sensitive anatomy in sometimes a casual manner render social media posts potentially unprofessional and disrespectful [4]. Many have questioned the ethics of such practices and called to maintain ethical and professional standards for the development of more structured regulatory oversight and guidance [10].

Obviously, guidelines are necessary to preserve patients' trust and protect public opinion [4]. Unfortunately, establishing internationally recognized ethical and professional social media guidelines for a plastic surgery practice is not easy [5]. Aesthetic plastic surgeons being professional practitioners with a serious responsibility towards both their profession and patients must maintain the highest standard of ethical behaviour. Practice websites and social media should always remain educational and expert driven [8]. Moving forward, the aesthetic plastic surgery specialty would benefit from evolving social media professional and ethical guidelines [4] applicable not only locally but also globally on an international level.

Unfortunately, plastic surgery literature does not offer a concrete definition of online social media professionalism and does not address what constitutes both professional and ethical conduct $[4,6]$. The ability "to communicate and interact in a respectful and productive manner" is one aspect of professionalism [4]. Nevertheless, despite published guidelines of the American Medical Association in 2011 and of the Federation of State Medical Boards, it is difficult to discern what constitutes respective, productive, and professional content. In fact, what defines a post as unprofessional is also not clear [4].

Bennett el al. [4] in 2018 have conducted an exhaustive search of the literature to address ethical principles related to social media. General guidelines put forth by the authors provide an excellent supplement to the American Society of Plastic Surgeons code of ethics; if implemented, they can effectively avoid potential pitfalls of social media engagement [6]. Most importantly, they recommend use of disclaimers that information provided on the social media is not a substitute for a consultation [5].

Implementation of Bennett et al. guidelines or as a matter of fact any other guidelines cannot be taken for granted. Unless aesthetic plastic surgeons chose voluntarily to follow these guidelines, professional associations do not have the political and legal power to enforce their application [8]. Surgeons embracing whatever means necessary to advertise without established standards for policing themselves must keep in mind that "historically, when professionals have failed to self-regulate, it often falls to the attorneys, lawmakers, and governing bodies to intervene on behalf of the public" $[4,5]$.

\section{References}

1. Mendelson BC (2008) Discussion: aesthetic/cosmetic surgery and ethical challenges. Aesth Plast Surg 32:840

2. Morrison CM, Rotemberg SC, Moreira-Gonzalez A, Zins JE (2008) A survey of cosmetic surgery training in plastic surgery programs in the United States. Plast Reconstr Surg 122:1570 
3. Tanna N, Patel NJ, Azhar H, Granzow JW (2010) Professional perceptions of plastic and reconstructive surgery: what primary care physicians Think. Plast Reconstr Surg 126:643

4. Bennett KG, Berlin NL, MacEachern MP, Buchman SR et al (2018) The ethical and professional use of social media in surgery: a systematic review of the literature. Plast Reconstr Surg $142: 388 \mathrm{e}$

5. Furnas H (2018) Discussion: the ethical and professional use of social media in surgery: a systematic review of the literature. Plast Reconstr Surg 142:399e

6. Gosman AA (2018) Discussion: the ethical and professional use of social media in surgery: a systematic review of the literature. Plast Reconstr Surg 142:403

7. Mess SA, Bharti G, Newcott B, Chaffin AE et al (2019) To post or not to post: plastic surgery practice marketing, websites, and social media? Plast Reconstr Surg Glob Open 25:e2331
8. Ghavami A (2018) Discussion: the ethical and professional use of social media in surgery: a systematic review of the literature. Plast Reconstr Surg 142:401e

9. Montemurro P, Cheema M, Hedén P (2018) Patients' and surgeons' perceptions of social media's role in the decision making for primary aesthetic breast augmentation. Aesthet Surg J 38:1078

10. Dorfman R, Vaca EE, Fine NA, Schierle CF (2017) The ethics of sharing plastic surgery videos on social media: systematic literature review, ethical analysis, and proposed guidelines. Plast Reconstr Surg 140:825

Publisher's Note Springer Nature remains neutral with regard to jurisdictional claims in published maps and institutional affiliations. 